\title{
Domestic Solid Waste Management Following Circular Economy Model
}

\author{
Nguyen Thi Thu Quynh ${ }^{1}$ \& Nguyen Quoc Hung ${ }^{2}$
}

${ }^{1}$ Faculty of Economics and Rural Development, Vietnam National University of Agriculture, Hanoi 131000, Vietnam

${ }^{2}$ Ministry of Natural Resource and Environment, Hanoi 129100, Vietnam

\begin{abstract}
Along with socio-economic development, the volume of domestic solid waste in Vietnam is increasing by $12 \%$ annually. The current management model of domestic solid waste presents many limitations: low collection rate, lack of proper treatment, and low levels of recycling and reusing rates but high rates of buried waste and pollution. Published research and overviews of practical implementation of solid waste management models in typical countries around the world have shown the need to innovate domestic solid waste management in Vietnam following the circular economy model to increase the economic efficiency of resources and to minimize polluting the environment. Accordingly, state management of domestic solid waste needs to be reformed synchronously to ensure the development of a closed cycle of waste from identifying generators, classifying waste at sources, collecting, transporting, and treating waste, to the consumption of recycled waste.
\end{abstract}

\section{Keywords}

Domestic solid waste, circular economy model, recycled

\section{Introduction}

Along with socio-economic development, the volume of domestic solid waste (DSW) in Vietnam is increasing rapidly and becoming an urgent environmental problem. High population growth, in combination with rapid industrialization and urbanization, have resulted in the growth of waste generation. It is estimated that the volume of DSW in Vietnam has experienced a growth of 10-16\% per year (World Bank, 2018). Thus, effective management of DSW is required to prevent harmful effects on the environment and society.

Recognizing this problem, in recent years, the Vietnamese

Received: May 28, 2020 Accepted: November 16, 2020

\section{Correspondence to} nttquynh@vnua.edu.vn government and authorities have made great efforts in the management of DSW. However, after the implementation process, there are still many shortcomings, namely the legal and policy system on DSW management is still incomplete and overlapped; the 
organization and assignment of responsibilities for DSW are still fragmented and lack uniformity, making it difficult to implement; the implementation of approved DSW management planning in localities is still slow; investments in DSW management are limited; there is a lack of appropriate regulations to attract capital investment resources from society; the inspection and examination of law enforcement are still limited; and sanctions regulating violations of DSW management are not strong enough (Nguyen Trung Thang, 2019). Moreover, the current traditional model of DSW management - a linear economy which follows the principle of "take - make - waste" (We "take" resources from the ground to "make" products, which we use, and, when we no longer want them, "throw" them away) is no longer working for all economic actors. Following this model, only $62-90 \%$ of generated waste is collected and processed; many types of useful DSW are not recycled for reuse, and $71 \%$ of DSW is buried or burned wastefully and pollutedly (Ministry of Natural Resources and Environment, 2019; 2020). Typically, the leachate at landfill sites is discharged directly to the environment, allowing it to infiltrate and directly impact the water environment, and diffuse pathogens creating serious impacts on the environment and human health (Ministry of Natural Resource and Environment, 2017). A study in Lang Son province addressed that the rate of people with illnesses and diseases such as diarrhea, dermatology conditions, and respiration problems, etc., at the affected areas of the landfill sites is much higher than those of the unaffected areas (Ministry of Natural Resources and Environment, 2011).

An overview of studies and practical implementation of DSW management models in several typical countries around the world shows the need for reforming the state management of DSW in Vietnam following the circular economy model (Luong Thu Thuy, 2019). The circular economy model was recognized and implemented very early in some Western countries such as Sweden, Germany, and Japan, but has been mentioned in Vietnam only recently (Preston, 2012; Alanetal., 2016; Luong Thu
Thuy, 2019). The concept of the circular economy model aims to redefine growth and focuses on positive society-wide benefits (World Economic Forum, 2014). It entails gradually decoupling economic activity from the consumption of finite resources and designing waste out of the system (Macarthur, 2017). The highlight of the model is to treat DSW as a renewable resource, requiring a closed cycle process with the participation of many actors to create a primary and secondary market for DSW (Vietnam Business Council for Sustainable Development, 2019). The goal of the model is to standardize the activities of the actors involved in the closed cycle process to minimize the emissions causing waste and environmental pollution in order to achieve economic - social environment efficiency. In this paper, the authors have generalized the current state of DSW in Vietnam and appraised the implementation of the current traditional DSW management model to address the need for reforming the DSW management model following the circular economy model.

\section{Methodology}

The authors applied the desktop study method to review the related published scientific articles and specialized reports related to the circular economy model. The Proquest Central and the Google search for academic articles using the keyword "circular economy" were applied. In addition, information and data on the real situation of domestic solid waste in Vietnam were collected and reviewed from annual national environmental status reports published by the Ministry of Natural Resources and the Environment. Descriptive and comparative statistical methods were used to reflect the current situation of DSW in Vietnam over time, by locality, and by region.

\section{Results and Discussion}

According to Vietnam Standards (TCVN 6705-2009), domestic solid waste includes solid waste generated from households, commercial businesses, and agencies. According to Decree No. 38/2015/ND-CP of the government dated 
April 24, 2015, on the management of waste and discarded materials, domestic solid waste (also called household garbage) means solid waste generated in the daily activities of humans. Solid waste is characterized by a solid or paste form (also called sludge) discharged from production, businesses, services, daily life, or other activities (Government, 2015).

Also in this Decree, daily-life solid waste is classified at its source in accordance with the purpose of management and treatment into the following groups:

(a) Biodegradable organic group (leftovers, leaves, vegetables, fruits, and animal carcasses);

(b) Reusable and recycled group (paper, plastic, metal, rubber, plastic, and glass); and

(c) Others.

Current status of domestic solid waste in Vietnam

\section{Volume generated}

According to the survey assessing the status of DSW performed by the Ministry of Natural Resources and the Environment, from 2010 to 2018 , the amount of generated DSW increased an average of about $12 \%$ per year. In 2015, the country generated a total DSW volume of about 42,789 tons/day, and by 2018 this figure increased to more than 61,600 tons/day, of which the volume generated in urban areas was more than 37,200 tons/day and the respective number of rural areas was more than 24,400 tons/day (Ministry of Natural Resources and the Environment, 2020). In particular, Ho Chi Minh City was the locality with the largest amount of
DSW generated, about 9,129 tons/day, Hanoi city ranked second with 6,500 tons/day, and Tuyen Quang was the locality with the least amount of waste generation, only 0.178 tons/day (Table 1).

Observing the volume of DSW generated by economic regions (Figure 1) shows that the Southeast region had the highest generated volume, accounting for $31.5 \%$ of the total domestic solid waste volume, whereas the Central Highlands and the Northern Midlands and Highlands had the lowest generated volumes in the country. This clearly shows a positive correlation between the proportion of the volume of DSW generated to the speed of economic development and urbanization of the localities and economic regions.

\section{Categories of domestic solid waste}

According to the composition of domestic solid waste, organic waste accounted for the largest proportion and inorganic waste accounted for a lower proportion (Table 2). Among inorganic wastes, the proportion of plastic and nylon, paper, and metal was relatively high, which poses a need to recycle and reuse these periodically to avoid wasting and causing pollution pressure on the environment.

\section{Traditional model of domestic solid waste management}

The typical traditional model of DSW management in urban areas is described in Figure 2 (World Bank, 2018).

Accordingly, after generating domestic solid waste, generators including households,

Table 1. Volume of domestic solid waste generated in localities across Vietnam in 2018

\begin{tabular}{ccc}
\hline Ranking & Province & $\begin{array}{c}\text { Average waste generated per day } \\
\text { (tons) }\end{array}$ \\
\hline Most DSW generated & Ho Chi Minh city & 9,128 \\
1 & Hanoi & 6,500 \\
2 & Thanh Hoa & 2,246 \\
3 & Binh Duong & 1,764 \\
4 & Dong Nai & 1,838 \\
5 & Tuyen Quang & 0.178 \\
63 & Bac Kan & 0.191 \\
62 & Kon Tum & 0.212 \\
61 & Dien Bien & 0.264 \\
60 & Ha Nam & 0.275 \\
\hline
\end{tabular}

Source: Ministry of Natural Resources and Environment (2020). 


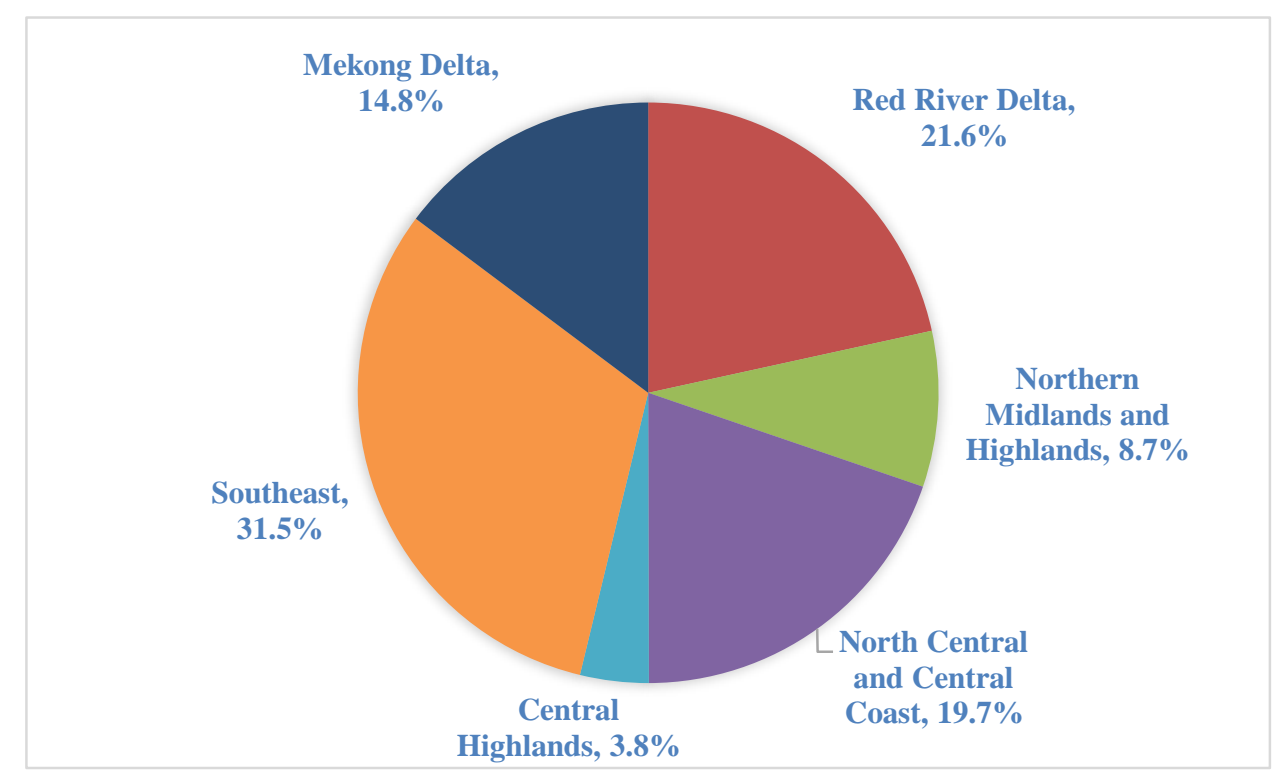

Figure 1. Volume of DSW generated by economic region, 2018 Source: Ministry of Natural Resource and Environment (2020).

Table 2. Categories of domestic solid waste

\begin{tabular}{lccc}
\multicolumn{1}{c}{ Categories } & Big cities in Vietnam & Hanoi & Hai Phong \\
\hline Organic wastes & $50.2-68.9$ & 51.9 & $46.0-49.8$ \\
Plastic and nylon & $3.4-10.6$ & 3.0 & $12.2-14.2$ \\
Paper and cardboard & $3.3-6.6$ & 2.7 & $3.8-4.2$ \\
Metal & $1.4-4.9$ & 0.9 & $0.1-0.2$ \\
Glass & $0.5-2.0$ & 0.5 & $0.8-0.9$ \\
Inert materials & $14.9-28.2$ & 38.0 & $23.9-24.7$ \\
Rubber and leather & $0.0-5.0$ & 1.3 & 0.6 \\
Animal and plant tissue & $1.5-2.5$ & - & - \\
Hazardous wastes & $0.0-1.0$ & - & - \\
Others & - & Textiles: 1.6 & $8.6-10.5$
\end{tabular}

Note: (-) Not available

Source: World Bank(2018).

businesses, shops, and streets do not or rarely classify waste at the source. Waste classification activities are most frequently carried out in commercial centers and supermarkets. In households, the classification activities focus on classifying the reusable and recycled components including plastic, cardboard, paper, and metal for selling as scrap to individual collectors.
According to World Bank (2018), 91\% of this waste is collected, and the remaining $9 \%$ of DSW is discharged indiscriminately into the environment. The amount of solid waste is collected by two actors: one is URENCO, the urban environment sanitation company in big cities, or private waste collection companies that collect $85 \%$ of the waste, while the remaining $6 \%$ is collected by individual collectors (mainly 


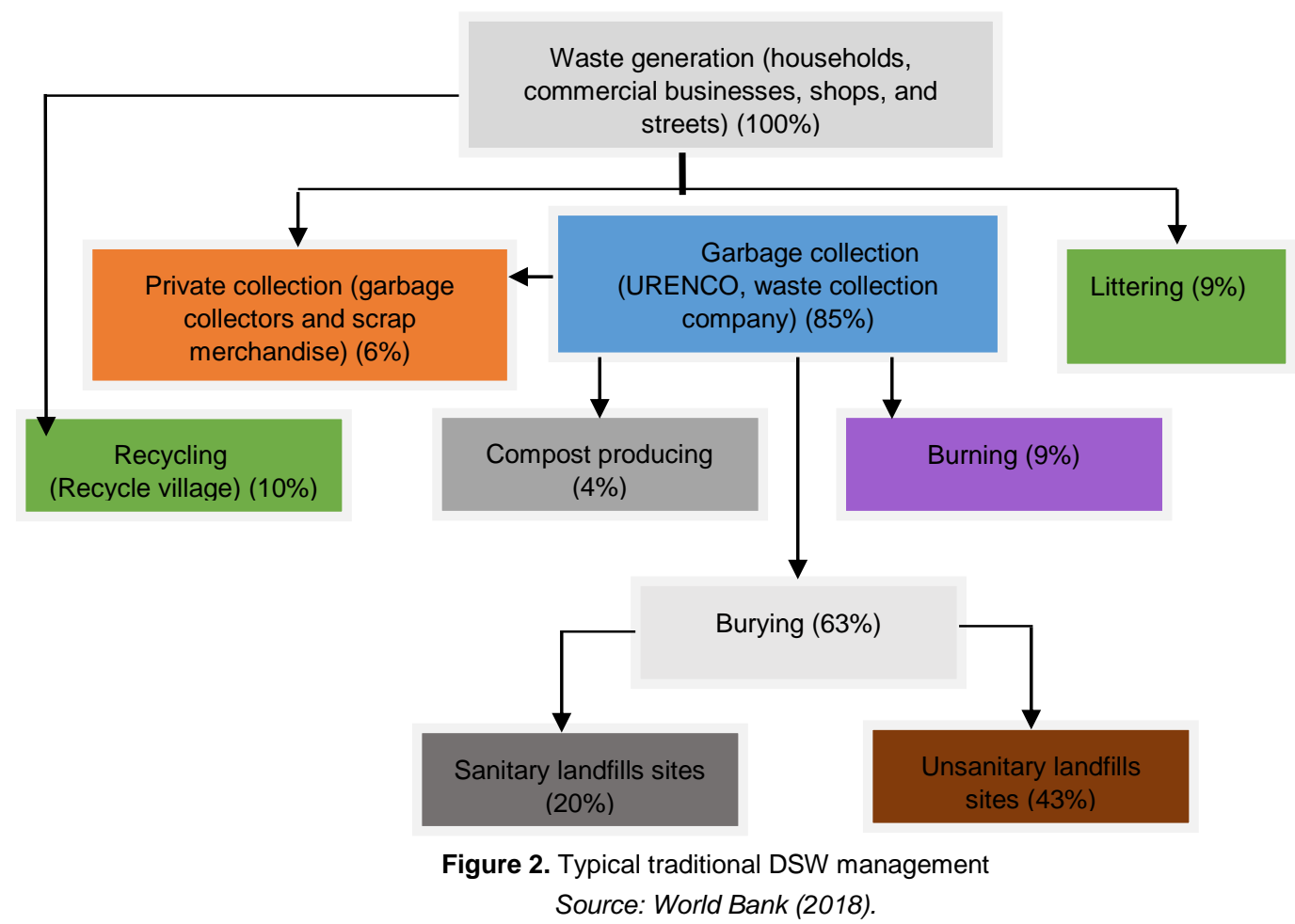

collecting the recycled inorganic wastes like plastic, paper, and metal).

Waste transportation is carried out by environmental companies using small garbage trucks to transfer DSW to collection points or transfer stations, and using specialized trucks to deliver DSW to the landfills and other treatment facilities. However, the hygiene of the collection trucks and transfer stations are not good, resulting in the effluent discharge of wastewater, which attracts mosquitoes and flies, and has a strong stench that negatively affects the people living nearby. Especially, garbage trucks and specialized trucks often operate during rush hour in the afternoon, causing local traffic congestion in many streets.

DSW after collection is mainly taken to landfills (63\%), and 28\% (about 14,000 tons/day) is taken to different treatment facilities ( $10 \%$ for recycling, $4 \%$ for compost production, and $14 \%$ for burning). Thus, theoretically, only $28 \%$ of the treated DSW has the opportunity to return to reserve the production and living activities of citizens. The remaining $63 \%$ is buried wastefully. Moreover, $43 \%$ of this DSW is buried in unhygienic landfills, with high risks of environmental pollution.
The traditional model of DSW management reveals some limitations. Firstly, economic growth, population growth, and strong urbanization result in a huge volumes of waste, which is increasing rapidly every year, especially in big cities (especially Hanoi and Ho Chi Minh City). Secondly, the system of collecting, sorting, and treating waste is complex and laborintensive, and the recycling market is occupied by an informal group. Thirdly, inadequate legal frameworks, and inadequate monitoring and supervision are causing environmental problems that increase people's health risks (commonly due to the activities of informal groups in the handicraft villages that can generate or handle significant amounts of hazardous waste). Fourthly, there is a lack of a "polluter must pay principle" with very low collection and treatment fees levied on households and other emission units, and at least $80 \%$ of treatment costs are subsidized by the government. Therefore, it is necessary to renovate the DSW management model to improve its effectiveness.

\section{Circular model of domestic solid waste management}

According to the proposed circulation economic model, DSW, which emanates from 


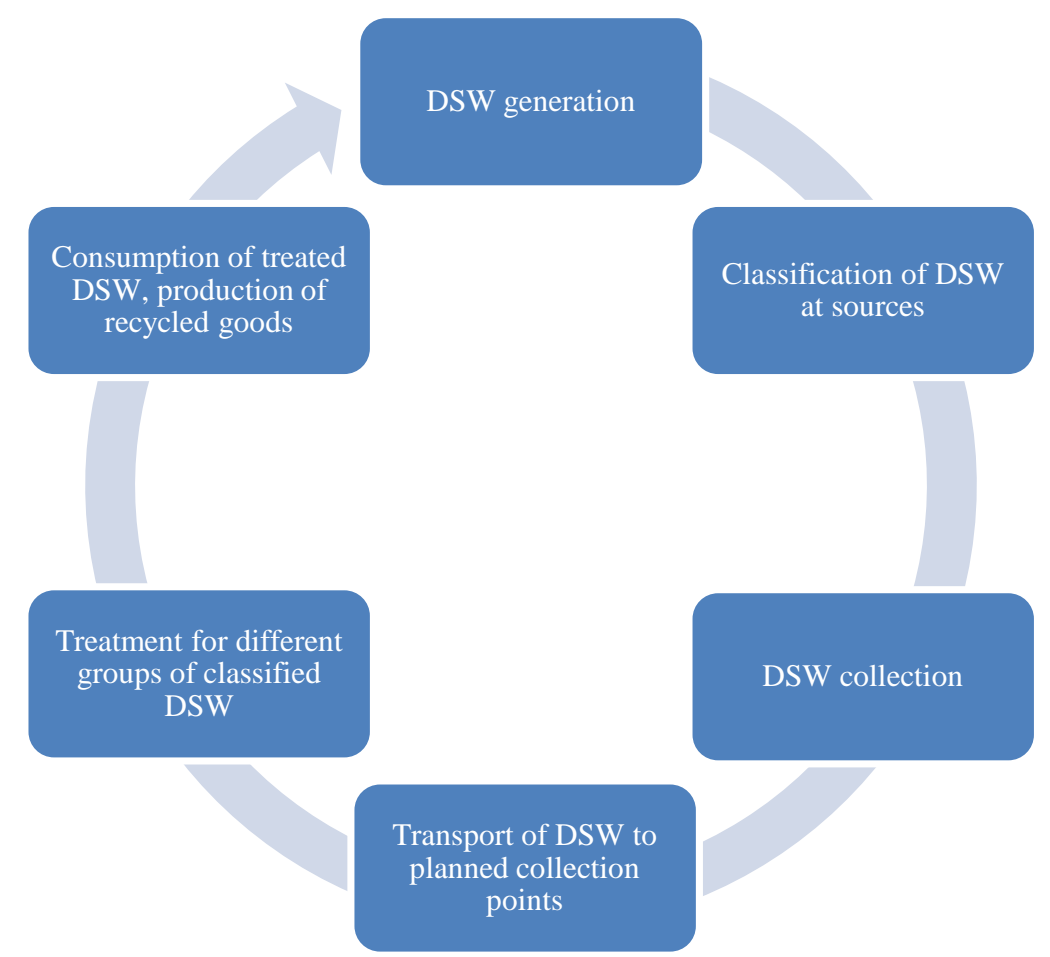

Figure 3. The circular domestic solid waste management model

generators through a process, becomes processed and recycled products to come back to serve these entities (Figure 3). The objective of the circular model of DSW management is to minimize emissions to the environment by building a closed cycle of waste.

\section{Step 1: Identify generators}

According to the circular economic model, the first step is to identify and manage the source of domestic solid waste. For each source, it is necessary to promulgate mandatory regulations and sanctions to require DSW generators to classify waste into regulated groups at the source. At the same time, properly identifying the generators will help to ensure the implementation of the principle of "polluters must pay", creating financial sources for the implementation of DSW collection and treatment activities in the future.

Step 2: Classify domestic solid waste at the source

According to the World Bank (2018), there are many criteria for classifying DSW, and the application of such criteria depends on the objectives and level of domestic solid waste treatment in each country. However, the most basic criterion is to separate organic and inorganic components.

The organic content in DSW can account for $50-70 \%$ of the total of solid waste, and organic waste is considered a source of raw materials for the production of high-quality compost or biogas. Therefore, focusing on waste delimitation and classification in order to collect a large volume of organic waste is considered a low-cost strategy to reduce the need for landfills while improving the efficiency of recycling DSW.

Next is the classification of inorganic waste components. Inorganic waste containing components such as plastic, paper, and metal needs to be collected for recycling. The remainder can become fuel but should be treated first to reduce the proportion of inert materials such as sand, gravel, and other non-combustible materials to meet the requirements of burning and co-burning to create energy for people's daily lives.

The effectiveness of waste classification at the source has been reported in many countries. In Germany, the Green Dot system was introduced as a mandatory regulation on waste 
classification at the source. The key point of this system is that manufacturers and retailers have to pay "Green Dot" fees for their products: the more packaging a product has, the higher the fee. Although Germany has 30 million tons of waste every year, this system has helped to reduce the components of paper, cardboard, glass, and metal. The German media predicted that the "Green Dot" system helps to reduce 1 million tons of waste each year (Thanh Thao, 2018), so they have to recycle less amounts of DSW.

In Japan, every type of waste you want to throw must be put into separate bags by color. For example, flammable waste will be put into yellow bags and the green bags are for nonburnable waste. If you do not comply with this regulation, your garbage bag will be returned with an "embarrassing ticket" to remind you to sort your waste. More strict regulations can be found in Korea, where not all garbage bags can be disposed of everywhere. Types of garbage bags are regulated depending on each region, each country, and each city. If you bring the garbage bags of the Gangnam area to Songpa-gu to throw them away, you can be fined (JD, 2018).

Therefore, in Vietnam, it is necessary to set up a specific set of regulations on sorting waste at the source, modes of containing the waste, and a specific schedule for dumping garbage to ensure efficient collection. At the same time, there also needs to be a strict monitoring mechanism and severe sanctions imposed to prevent indiscriminate discharge into the environment. Singapore is still known as the cleanest country in the world thanks to its extremely severe sanctions for indiscriminate littering in public places.

\section{Step 3: Collecting domestic solid waste}

Indeed, there are still two types of collection forms in the world: primary collection (collecting garbage from each household) and secondary collection (transfer waste from collecting points or transfer stations to treatment facilities). However, the traditional management model of domestic solid waste in Vietnam shows that both forms of collection are not effective. According to reported data, the waste collection rates are about $85 \%$ in urban areas and $40 \%$ in rural areas, although actual figures may be lower (Ministry of Natural Resources and the Environment, 2020).

Primary collection is carried out by official actors (employees of sanitation companies) and informal actors (individual collectors). However, individual collector activities do not have a specific plan. They do not have personal protective equipment, only collect certain types of domestic waste, and create many unsecured scrap gathering yards near residential areas. As for the official collectors, they often collect all types of DSW at the same time, as there is no regulation and collection schedule for each type of waste as classified.

Therefore, it is necessary to change both the form and the method of collection. Accordingly, it is essential to formalize the activities of informal individual collectors through the signing labor contracts with them while simultaneously prohibiting separate collection activities, and only allowing concentrated collecting points to be in operation (in residential areas, in supermarkets). At the same time, it is necessary to arrange specific collection schedules for each type of DSW which have been classified from the source to ensure the effectiveness of future treatments.

Step 4: Transporting domestic solid waste to the planned collection points

In this step, it is necessary to develop and readjust the planning of transfer stations, landfill sites, and treatment facilities to ensure that they are far from residential areas and are designed to comply with hygienic and safety conditions to avoid causing congestion or unsafe situations for surrounding residential areas. This requires the strong participation of all levels of the government and strict regulations on technical equipment and facilities for these activities.

Also, each different type of domestic solid waste needs to be transported to different collection points and treatment facilities, rather than a mass and aggregation situation that makes it difficult for later steps. 
Step 5: Treatment of the classified domestic solid waste

According to Article 19 in Degree No. $38 / 2018$ /ND-CP, a recycling activity is the activity of treating DSW by various technologies (Government, 2015), such as organic fertilizer processing technology; combustion technology; sanitary landfill technology; technology for recycling, energy recovery, and producing products from the useful composition of dailylife solid waste; and other environmentally friendly technologies.

Accordingly, the purpose of recycling is to ensure that DSW after being treated and recycled will become useful products that can serve the daily lives and production activities of people.

Solid waste and solid waste treatment are big issues in many countries around the world. However, nowadays, many developed countries, especially countries in Europe, are leading the way in waste treatment solutions. To them, solid waste is considered a valuable resource and a business opportunity that not only brings economic returns but also helps to protect the environment.

Sweden has been a leader in recycling solid waste for many years. Currently, the rate of recycled DSW is up to $99 \%$. This country even has to import waste from other countries for continuously operating its recycling plants which have been creating much added value to their economy.

Norway is also one of the world's leading countries in recycling plastic waste. Evidence shows that $97 \%$ of plastic bottles from this country have been recycled, $92 \%$ of which return to high-quality plastic and can continuously contain drinking water. The life cycle of some plastic bottles in Norway can be recycled up to 50 times. This makes the Nordic nation a model for the whole world in the field of environmental protection (Lan Huong, 2019).

Step 6: Consumption of treated domestic solid waste and production of recycled goods

The results of the series of improvements listed above in the DSW management process only make sense if the products generated from the waste treatment and recycling process are accepted for consumption by actors in the economy.

The purpose of the circular economy model is to minimize the amount of DSW disposed into the environment, which can result in the consequences of waste resources (for organic solid waste) and, more seriously, causing environmental pollution (for hazardous solid wastes). However, there are still many people who believe that garbage products are not clean or hygienic for direct human consumption. Therefore, it is necessary to propagate to change the people's awareness about the recognition and evaluation of products from recycled waste. This will create a real market demand for processed and recycled waste products such as organic fertilizer, plastic resins, gas, and electricity, etc. In addition, some economic incentives should be presented to stimulate the demand for these products such as discounted prices (compared to higher adjusted prices of non-recyclable items), and tax exemptions or tax reductions for organizations and individuals. In Germany, the government has published information and requires supermarkets to provide more environmentally friendly recycling bags, canvas bags, and paper bags. If customers require plastic bags, they must pay instead of the bags being given for free as before.

In addition, other administrative measures should also be considered by enhancing the social responsibilities of individuals, businesses, agencies, and units in consuming recycled products to minimize environmental pollution. It is essential that every stakeholder must acknowledge that the consumption of these products is their responsibility and obligation to the community and to themselves.

After the consumption of processed and recycled waste products takes place, a new emission process appears. The circular model of DSW not only results in economic effectiveness but also social and environmental effectiveness.

Innovating the state management of domestic solid waste following the circular economy model 
In order to develop and implement the model of circular economy in domestic solid waste management, it is necessary to innovate the state management work in this field in advance. Specifically, the following solutions need to be studied and implemented synchronously to get the highest effectiveness:

Firstly, it is necessary to complete the guidelines, policies, and regulations on the classification, collection, and treatment of DSW in the direction of improving the implementation of compulsory social responsibility for each citizen, each unit, and each enterprise in order to protect themselves and the community towards sustainable development.

Secondly, it is necessary to clearly assign the responsibilities of the ministries, agencies, and localities in performing the state management functions of domestic solid waste to avoid overlapping, unclear, and inconsistent responsibilities which lead to low management effectiveness. Especially, it is necessary to enhance the role of the Environmental Police and enhance the role of the community in inspecting and supervising the implementation of regulations and laws on DSW.

Thirdly, it is necessary to develop and adjust the planning of collection sites, treatment facilities, and recycling plants, so they are concentrated, large scale, separate for each type of DSW, and far from crowded residential areas. This is the way to ensure the effectiveness of investments and minimize the negative impacts of these activities on people's living environments.

Fourthly, it is necessary to innovate and promote the attraction of public-private partnerships in the field of solid waste collection and treatment in order to avoid relying too much on the current budget. It is essential to treat DSW as a resource to be produced, processed, recycled, and marketed.

Fifthly, it is necessary to renovate the financial revenue - expenditures in the collection and treatment of DSW. Accordingly, the collection and treatment fee for DSW should be raised to the highest acceptable threshold of households (1-1.5\% of income/year according to international practices) to ensure funding for efficient collection and treatment activities (World Bank, 2018). Regarding the expenditure structure, it is necessary to pay more attention to and to spend more on advanced and modern treatment technologies to reduce the proportion of expenses for small collection activities as at present. Collection should be renewed in the direction of reducing the frequent use of manpower, with small, inefficient tools, to using modern equipment, according to the periodic plan.

Sixthly, it is necessary to improve the propaganda activities on the need for good management of DSW in people's lives, and the responsibilities and rights of people in participating in DSW management from classifying, collecting, recycling, treating, and consuming recycled waste products.

\section{Conclusions}

The current situation and forecast of Vietnam's domestic solid waste by 2030 show that authorities should spend more effort in managing waste, otherwise they will cause unpredictable consequences in terms of economic, social, and environmental impacts, which in turn can affect people's lives, hindering the goal of sustainable development.

Although the government and authorities have recently put great effort into the management of DSW, the implementation of the state management of this field still revealed many shortcomings. Therefore, in the coming years, the research indicates that it is necessary to innovate the state management of DSW following the circular economic model from the viewpoint of considering DSW as a renewable resource. It is necessary to build up the primary and secondary markets for domestic solid waste in a closed cycle process with the participation of many actors. Their activities should be standardized to minimize the external emissions that cause waste and environmental pollution in order to achieve economic - social environmental efficiency. To achieve this goal, the state management of domestic solid waste should implement some of the above-proposed 
solutions synchronously to achieve the highest effectiveness and management efficiency.

\section{Acknowledgments}

We would like to thank the Ministry of Natural Resources and Environment for supporting and sharing the Status of National Environment survey results to write this paper.

\section{References}

Alan M., Keith S.\& Kathryn H. (2016). The Circular Economy: An interdisciplinary exploration of the concept and application in a global context. Retrieved from https://hullrepository.worktribe.com/preview/385013/2016-0522\%2012595\%20Haynes.pdf on September 2, 2020.

Luong Thu Thuy (2019). Promoting circular economy models in Vietnam for the sustainable development. Retrieved from https://www.quanlynhanuoc.vn/2020/12/08/thuc-daynen-kinh-te-tuan-hoan-o-viet-nam-nham-phat-trienben-vung-dat-nuoc on May 1, 2020 (in Vietnamese).

World Economic Forum (2014). Towards the Circular economy: Accelerating the scale-up across global supply chains. Geneva, Switzerland.

Government (2015). Decree No. 38/2015/ND-CP on waste and scrap management, dated 24/4/2015. Hanoi (in Vietnamese).

JD (2018). Watch and "go crazy" with the garbage classification regulations of some famous clean countries in the world. Retrieved from https://cafebiz.vn/xem-va-phat-dien-voi-quy-dinhphan-loai-rac-cua-mot-so-quoc-gia-sach-co-tiengtren-the-gioi-20181123084113661.chn on May 15, 2020.

Lan Huong (2019). Waste: resources or disaster? Retrieved from http://quochoi.vn/UserControls/Publishing/News/Bin
hLuan/pFormPrint.aspx? UrlListProcess=/content/tint uc/Lists/News\&ItemID=41630 on May 12, 2020.

Macarthur E. (2017). Ellen Macarthur Foundation. Retrieved from https://www.ellenmacarthurfoundation.org/circulareconomy/what-is-the-circular-economy on September $2,2020$.

Ministry of Natural Resources and the Environment (2011). 2011 National Environment Report. Hanoi: Natural Resources and Maps Publisher (in Vietnamese).

Ministry of Natual Resources and the Environment (2017). 2017 National Environment Report on Waste management. Hanoi: Vietnam Natural Resources and Maps Publisher (in Vietnamese).

Ministry of Natural Resources and the Environment (2019). Draft of Project to strengthen domestic solid waste management capacity in Vietnam. Hanoi (in Vietnamese).

Ministry of Natural Resources and the Environment (2020). Draft of National Environmental Status Report 2019. Hanoi.

Preston F. (2012). A Global Redesign: Shaping the Circular Economy. London: Chatham House :The Royal Institute of International Affairs.

Nguyen Trung Thang (2019). Overview of solid waste management in the world and some solutions for Vietnam. Journal of Environment. 9. Retrieved from https://thegioimoitruong.vn/tong-quan-ve-quan-lychat-thai-ran-tren-the-gioi-va-mot-so-giai-phap-choviet-nam.html_on May 12, 2020 (in Vietnamese).

Thanh Thao (2018). Vietnam nature and environment protection association. Retrieved from http://www.vacne.org.vn/van-hoa-phan-loai-rac-ocac-nuoc/217000.html on May 12, 2020 (in Vietnamese).

Vietnam Business Council for Sustainable Development (2019). CEO guide to circular economy VI. Hanoi: Accenture strategy (in Vietnamese).

World Bank (2018). Assessment of domestic and hazardous industrial waste management: options and actions to implement the national strategy. Washington DC: Publishing Department, World Bank. 